\title{
Erratum to: Soil salinization in the agricultural lands of Rhodope District, northeastern Greece
}

\author{
V. Pisinaras $\cdot$ V. A. Tsihrintzis · \\ C. Petalas $\cdot$ K. Ouzounis
}

Published online: 23 December 2009

(C) Springer Science+Business Media B.V. 2009

\section{Erratum to: Environ Monit Assess DOI 10.1007/s10661-009-0986-6}

It has come to Springer's attention that two paragraphs in the paper Soil salinization in the agricultural lands of Rhodope District, northeastern Greece, by Vassilios Pisinaras, Vassilios A. Tsihrintzis, Christos Petalas, Konstantinos Ouzounis (DOI 10.1007/s10661-009-0986-6) published in Environmental Monitoring and Assessment (EMAS), were copied virtually intact from the paper The agricultural impacts of irrigation induced waterlogging and soil salinity in

The online version of the original article can be found at http://dx.doi.org/10.1007/s10661-009-0986-6.

V. Pisinaras · V. A. Tsihrintzis $(\varangle) \cdot$ C. Petalas Laboratory of Ecological Engineering and Technology, Department of Environmental Engineering, School of Engineering, Democritus University of Thrace,

67100 Xanthi, Greece

e-mail: tsihrin@otenet.gr

K. Ouzounis

Laboratory of Environmental Chemistry, Department of Environmental Engineering, School of Engineering, Democritus University of Thrace, 67100 Xanthi, Greece the Arkansas Basin, by Houk et al., J of Agricultural Water Management 85:175-183. While the two papers are totally different in concept and the EMAS authors had cited the Arkansas paper at the beginning of these paragraphs, they admit there was an oversight in the way they identified these two paragraphs. They should have used italics and quotes, or even totally omitted the two paragraphs. The authors of the paper in EMAS wish to sincerely apologize for this mistake. 